Graphical Abstract

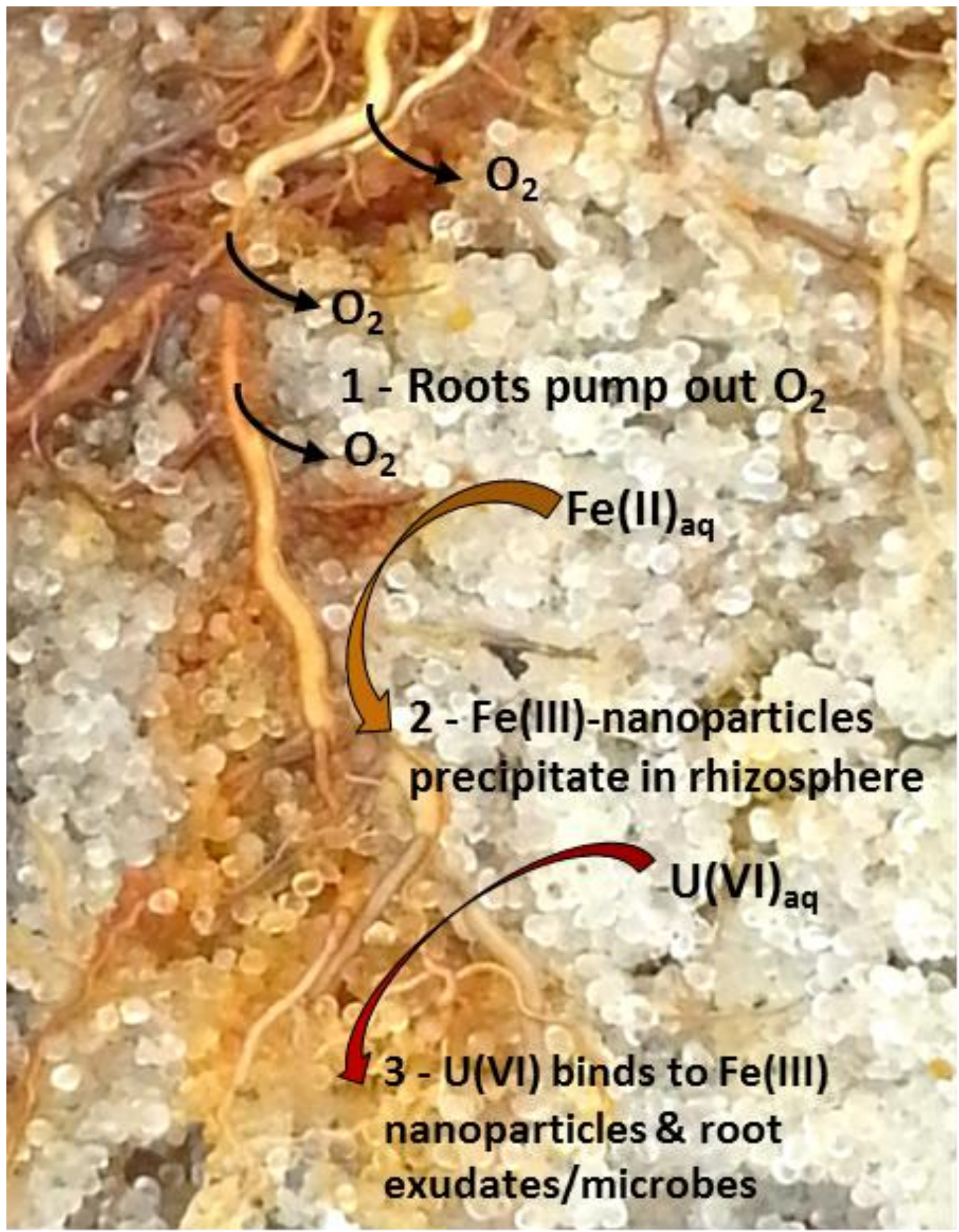




\section{Iron Mineralogy and Uranium-Binding Environment in the Rhizosphere of a Wetland Soil}

Daniel I. Kaplan ${ }^{\mathrm{a}^{*}}$, Ravi Kukkadapu ${ }^{\mathrm{b}}$, John C. Seaman ${ }^{\mathrm{c}}$, Bruce W. Arey ${ }^{\mathrm{b}}$, Alice C. Dohnalkova ${ }^{\mathrm{b}}$, Shea Buettner ${ }^{\mathrm{c}}$, Dien Li ${ }^{\mathrm{a}}$, Tamas Varga ${ }^{\mathrm{b}}$, Kirk G. Scheckel ${ }^{\mathrm{d}}$, Peter R. Jaffé

${ }^{a}$ Savannah River National Laboratory, Aiken, South Carolina 29808, United States

${ }^{\mathrm{b}}$ Environmental Molecular Sciences Laboratory, Pacific Northwest National Laboratory, Richland, Washington 99354, United States

c Savannah River Ecology Laboratory, University of Georgia, Aiken, South Carolina 29802, United States

${ }^{\mathrm{d}}$ US Environmental Protection Agency, National Risk Management Research Laboratory, Cincinnati, Ohio 45224, United States

${ }^{\mathrm{e}}$ Princeton University, Princeton, New Jersey 08540, United States

* Corresponding author, daniel.kaplan@ srnl.doe.gov, 803-725-2363

Research Paper

Submitted to Science of the Total Environment

Keywords: Root, X-ray Absorption Spectroscopy, Iron nanoparticles, Mössbauer 


\begin{abstract}
Wetlands mitigate the migration of groundwater contaminants through a series of biogeochemical gradients that enhance multiple contaminant-binding processes. The hypothesis of this study was that wetland plant roots contribute organic carbon and release $\mathrm{O}_{2}$ within the rhizosphere (plant-impact soil zone) that promote the formation of $\mathrm{Fe}$ (III)-(oxyhydr)oxides. In turn, these Fe(III)-(oxyhydr)oxides stabilize organic matter that together contribute to contaminant immobilization. Mineralogy and $U$ binding environments of the rhizosphere were evaluated in samples collected from contaminated and non-contaminated areas of a wetland on the Savannah River Site in South Carolina. Based on Mössbauer spectroscopy, rhizosphere soil was greatly enriched with nanogoethite, ferrihydrite-like nanoparticulates, and hematite, with negligible Fe(II) present. X-ray computed tomography and various microscopy techniques showed that root plaques were tens-of-microns thick and consisted of highly oriented Fenanoparticles, suggesting that the roots were involved in creating the biogeochemical conditions conducive to the nanoparticle formation. XAS showed that a majority of the $\mathrm{U}$ in the bulk wetland soil was in the +6 oxidation state and was not well correlated spatially to Fe concentrations. SEM/EDS confirm that $U$ was enriched on root plaques, where it was always found in association with $\mathrm{P}$. Together these findings support our hypothesis and suggest that plants can alter mineralogical conditions that may be conducive to contaminant immobilization in wetlands.
\end{abstract}




\section{Introduction}

Wetland environments are effective at mitigating the migration of many groundwater contaminants because of their unique combination of geochemistry, microbiology, and hydrology (Grybos et al., 2007; Kennish, 2002). These ecosystems promote the decay of plant litter to form soil organic matter (OM). The resulting OM has several direct and indirect properties that enhance the wetland soil's capacity to bind contaminants, including increasing microbial activity, lowering the oxidation state, and creating more surface binding sites (Bowden, 1987; Johnston, 1991; Schlesinger, 2009; Sposito, 2011). These conditions often lead to groundwater metals (Frohne et al., 2014; O'Geen et al., 2010) and radionuclides (Kaplan et al., 2013; Wang et al., 2014; Wang et al., 2013) becoming immobilized in the wetlands.

Contaminant $\mathrm{U}$ has been reported in wetlands associated with $\mathrm{U}$ mining operations (Wang et al., 2014; Wang et al., 2013) and nuclear material production (Bertsch et al., 1994; Chang et al., 2014; Sowder et al., 2005). Uranium is more mobile in its oxidized state, U(VI), which commonly forms strong complexes with carbonates and hydroxides, and is relatively soluble (Langmuir, 1978). Uranium in far less mobile in the reduced state, U(IV), which is appreciably less soluble than U(VI) and binds strongly to mineral and organic matter. Uranium(VI) can be readily reduced to $\mathrm{U}(\mathrm{IV})$ by dissolved and solid forms of $\mathrm{Fe}(\mathrm{II}), \mathrm{Mn}(\mathrm{II})$, and sulfides, and by $\mathrm{OM}$ and several naturally occurring microbes(Lovley, 1997; Wall and Krumholz, 2006).

Roots have long been known to alter soil microbiology, hydrology, and chemistry (Bronick and Lal, 2005). This is especially pronounced in wetlands where plants not only create steep $\mathrm{pH}$, plant nutrient, and organic $\mathrm{C}$ gradients, but they also create dissolved $\mathrm{O}_{2}$ gradients. Downward transport of oxygen through the plant into the soil is a physiological adaptation of wetland plants to enable them to grow in water-logged, reducing conditions (Bacha and Hossner, 1977; Chen et al., 1980; Mendelssohn and Postek, 1982). The oxygen introduced to the carbonrich rhizosphere, the root-impacted soil zone, promotes the abiotic and biotic oxidation of dissolved $\mathrm{Fe}(\mathrm{II})$ to form $\mathrm{Fe}(\mathrm{III})$-oxyhydroxide precipitates on the root surface, referred to as plaques (Gibberd et al., 2001; Thomas et al., 2005). Plaques can include several Feoxyhydroxides, including ferrihydrite, lepidocrocite, goethite, Fe-hydroxide, and siderite (Bacha and Hossner, 1977; Chen et al., 1980; Hansel et al., 2001; Taylor et al., 1984; Wang and Peverly, 1999). These mineral formations have been reported to be associated with several different plant species, including indigenous wetland plants, agricultural plants, and trees (Crowder and Macfie, 1986; Green and Etherington, 1977; Menhelssohn, 1993; Otte et al., 1989). The presence of plaques is largely controlled by plant type and the hydrological cycle and they can act as barriers to phytotoxic metals (Hansel et al., 2001; Otte et al., 1989; St-Cyr and Crowder, 1990). It is not clear how the plaque Fe-oxyhydroxides differ from those in the bulk soil. The high organic carbon and redox conditions in plaques are favorable for many Fe-reducing and Fe-oxidizing bacteria (Emerson et al., 1999; King and Garey, 1999). Biogenic Fe(II)/Fe(III) cycling may be an important process affecting other redox-active contaminants, such as U. Above pH 5.4, $\mathrm{Fe}(\mathrm{III})-\mathrm{U}(\mathrm{IV})$ precipitates in bioreduced soils have been detected by X-ray absorption fine structure (XAFS) (Kelly et al., 2008). Furthermore, phosphate has been reported to enhance U sorption on Fe(III)-oxides (Singh et al., 2012; Singh et al., 2010). U(VI) species initially associated with carbon- and phosphorus-containing ligands were transformed to U(IV) associated with Fe and uraninite (Kelly et al., 2010).

Uranium migration has been significantly attenuated in the Tims Branch wetland on the Savannah River Site (SRS) in South Carolina, a nuclear processing facility (Evans et al., 1992).

Of the 44 metric tons of depleted $U$ introduced between 1954 and 1985 into the Tims Branch 
system, 70\% remains in the wetland. Based on XAFS and sequential extraction characterization, most of the wetland U exists in association with OM (Bertsch et al., 1994; Li et al., 2015; Sowder et al., 2005). Furthermore, while this site is moderately acidic ( $\mathrm{pH}$ 5.5) and has microbes that have the potential to promote $\mathrm{U}$ reduction (including Geobacter spp. and sulfur reducing bacteria) (Turick et al., 2008) the $\mathrm{U}$ at the site exists almost exclusively as U(VI) (Bertsch et al., 1994; Li et al., 2015). Greenhouse mesocosm studies, simulating Tims Branch conditions, showed that $\mathrm{U}$ concentrations near the root were $3 \times$ greater than these in root-free soils (Chang et al., 2014; Jaffé et al., 2014; Li et al., 2015). Furthermore, the rhizosphere had a distinct color difference compared to the bulk soil; it was brick-red, whereas the bulk soil was either brown or yellowish white. The red coloration originated from Fe(III)-mineral formation. It was also shown that the composition of OM differed greatly between the rhizosphere and nonrhizosphere; the rhizosphere OM molecules generally had greater overall molecular weights, less aromaticity and a greater hydrophilic character (Kaplan et al., 2016).

The objective of this study was to build upon results from mesocosm studies (Chang et al., 2014; James and Rubin, 1986; Kim et al., 2003) and to conduct a field investigation to determine how rhizosphere and non-rhizosphere soil differ in terms of mineralogy and geochemistry that might influence uranium binding. Our hypothesis was that wetland plant roots contribute OM and release $\mathrm{O}_{2}$ within the rhizosphere that promote the formation of $\mathrm{Fe}(\mathrm{III})$-(oxyhydr)oxides. In turn, these Fe(III)-(oxyhydr)oxides stabilize organic matter that together contribute to contaminant immobilization. The general approach was to collect soils containing roots from the Tims Branch wetland and characterize subsamples designated as near (rhizosphere) and far (nonrhizosphere) from the roots. The samples were characterized using wet chemistry, and various types of spectroscopy and microscopy. Additionally, soil porewater samples were collected from depth-discrete diffusion samplers to provide information about the aqueous chemical conditions at the study site.

\section{Materials and Methods}

\subsection{Study site}

Tims Branch is a second-order stream located on the SRS and it drains an area of approximately $16 \mathrm{~km}^{2}$ before entering the Savannah River (Fig. 1). Tims Branch passes through M-Area, a former target and fuel processing facility for nuclear materials (Pickett, 1990). As a result of operations between 1954 and 1985, 44 tons of $U$ was released into the Tims Branch system, which accounts for $97 \%$ of the gross alpha activity released by SRS. As a remnant of former agriculture activities in the area, Tims Branch was dammed, resulting in the formation of Steeds Pond (Fig. 1). The sediment underlying Steeds Pond is especially contaminated with U because water in this stretch of Tims Branch was slow moving and as a result contaminated particles settled from suspension (Evans et al., 1992). The pond has since been drained, exposing most of the underlying sediment, except where braided tributaries presently exist. During the winter and spring, the braided tributaries are more extensive and deeper, while during the summer months, several of the tributaries dry up. The site receives an annual rainfall of 115 $\mathrm{cm} \mathrm{yr}^{-1}$, which is distributed evenly throughout the four seasons. The vegetation at the site is dominated by dense, robust-form clonal graminoids, including grass and sedge marsh vegetation types (Dixon et al., 1997).

\subsection{Sampling}


Porewater was collected from two depth-discrete diffusion samplers that were installed along Tims Branch in the area where Steeds Pond use to be (Fig. 1). The diffusion samplers have been described by MacDonald et al. (2013) (Fig. 2). Briefly, two of these 1-m long PVC samplers were placed about $30 \mathrm{~m}$ apart along the banks of Tims Branch at locations, referred to as \#1Contaminated and \#2-Contaminated location. The diffusion sampler consisted of $2060-\mathrm{mL}$ chambers $(3.5 \times 1.2 \times 0.9 \mathrm{~cm})$ stacked on top of one another with a polyethersulfone membrane $(0.22 \mu \mathrm{m}$ pore size) stretched over the front of the chamber openings to separate the soil from the chambers. Two $0.16-\mathrm{cm}$ (1/16 inch) Tygon tubes were embedded in the side of the PVC structure to connect each sampling chamber to above ground. The tubes were used to add deoxygenated, deionized water to the chambers. This water was permitted to equilibrate passively with the sediment pore water for three months before withdrawing the water samples from the 20 chambers. $\mathrm{pH}$ and Eh were measured in the field. All other analyses were measured in the laboratory as described in Section 2.3.

Three soil samples were collected: two near the diffusion samplers (\#1-Contaminated and \#2Contaminated), and the third from a minimally contaminated area just upstream of the M-Area discharge tributary (Background Sample) (Fig. 1). The Background soil sample was used to provide an uncontaminated analogue of the contaminated samples. For purposes of safety or cost, not all instruments used in this study could be used with radiological samples, and for that reason some analyses were conducted on the Background sample to provide insight about the biogeochemistry that may have occurred in the nearby radionuclide-contaminant area. The location of the Background sample was selected based on its similar vegetative, hydraulic, and topographic characteristics to the two contaminated samples. At each location, three relatively undisturbed $\sim 600$-g clumps of soil containing roots (Juncus effuses) were collected from the surface $15-\mathrm{cm}$ depth, placed in zip lock bags, and stored in an ice chest. Once at the Savannah River National Laboratory, the soil samples were placed in tripled zip lock bags; the space between each bag was filled with $\mathrm{N}_{2}$ gas, forming a double- $\mathrm{N}_{2}$ gas envelope around the samples. The samples were shipped over-night on blue-ice to the Environmental Molecular Sciences Laboratory (EMSL), where they were stored moist in a $4 \mathrm{C}$ refrigerator in the dark. There was no evidence that the gas envelopes had deflated prior to subsampling at EMSL.

The Background and \#1-Contaminated soil samples were divided into three subsamples: <2mm bulk subsample, rhizosphere subsample, and non-rhizosphere subsample. The bulk subsample (entire natural soil sample) was air dried, passed through a $<2-\mathrm{mm}$ sieve, and then characterized for general soil properties, as described in Section 2.3. The rhizosphere subsample was operationally defined as soils near the root (generally within $10 \mathrm{~mm}$ of the root) that had a red color. In a $\mathrm{N}_{2}$-glovebag, this subsample was manually separated with a spatula from the root and bulk soil; the remaining soil was referred to as the non-rhizosphere subsample. The subsamples were characterized at Pacific Northwest National Laboratory's EMSL facility.

\subsection{Chemical and mineralogical analyses}

Porewater samples from the depth-discrete diffusion samplers were analyzed in the field for $\mathrm{pH}$ and Eh. An acidified $0.45-\mu \mathrm{m}$ filtered subsample was analyzed for nitrate and sulfate by ion chromatography and for metals by inductively coupled plasma - mass spectroscopy. An unacidified sample was analyzed for total organic and inorganic carbon by catalytically 
combusting and oxidizing the $\mathrm{C}$ compounds to $\mathrm{CO}_{2}$ and then detecting the $\mathrm{CO}_{2}$ with a nondispersive infrared detector, using a Shimadzu 5000 analyzer.

The bulk soil was characterized using standard methods (Sparks, 1996). Eh and pH were measured in 1:1 soil:distilled-deionized water suspensions. Cation exchange capacity was determined by measuring the major cations exchanged by an unbuffered $0.2 \mathrm{M} \mathrm{KNO}_{3}$ solution. Total carbon, nitrogen and sulfur were measured with a LECO CNS-2000 analyzer. Fe(II)/(III) were measured by the colorimetric 1,10-phenanthroline method. The citrate-dithionitebicarbonate (CDB) extractable $\mathrm{Al}, \mathrm{Fe}, \mathrm{Mn}$, and $\mathrm{U}$ were determined by leaching each sample twice with the $\mathrm{CDB}$ solution at $80^{\circ} \mathrm{C}$. Total $\mathrm{Al}, \mathrm{Fe}, \mathrm{Mn}$, and $\mathrm{U}$ were determined by X-ray fluorescence. Mineral identification was conducted using X-ray diffraction spectroscopy (XRD) of the clay-size fraction $(<2 \mu \mathrm{m})$ of the bulk soil (Scintag XRD unit equipped with a copper Xray tube and a JADE XRD pattern processing software). It was not possible to conduct XRD of the rhizosphere and non-rhizosphere subsamples because of insufficient sample $(<0.5 \mathrm{~g}$ total sample for all analyses).

\subsection{Spectroscopy}

Microscopy and spectroscopy analyses were conducted on the rhizosphere and nonrhizosphere subsamples recovered from the Background and \#1-Contaminated soil sample. A brief description of these analyses is provided here and a more detailed description of these analyses and a list of spectroscopic and microscopic analyses performed on each sample (Table S1) are provided in the Supporting Information. As noted above, we conducted a full suite of analyses on the Background soil, but due to radiological safety concerns and limited sample size (rhizosphere subsamples), we were permitted to conduct only a subset of these analyses on the two contaminated soils. Mössbauer spectroscopy was conducted to identify and quantify Fe mineralogy using either a WissEl Elektronik (Starnberg, Germany) or a Web Research Company (St. Paul, MN) instrument. Analyses were conducted at various temperatures (including room temperature $(298 \mathrm{~K}), 150 \mathrm{~K}, 77 \mathrm{~K}, 35 \mathrm{~K}$, and $10 \mathrm{~K})$. Details related to instrumentation, data modeling, and interpretations are presented in the Supporting Information. An X-ray computed tomography system (XCT) was used to provide a nondestructive technique for visualizing roots and associated iron plaques and soil that were recovered from the Tims Branch wetland.

Reconstructed 3D images were used to provide information about the thickness and morphology of the plaque. The samples were scanned with an X-ray power of $70 \mathrm{kV}$ and $300 \mu \mathrm{A}$ current using $1 \mathrm{sec}$ exposure time per projection. The resolution was 25 by $25 \mu \mathrm{m} \mathrm{voxel}^{-1}$.

Micro-XRF ( $\mu$-XRF) maps and micro-XANES ( $\mu$-XANES) analyses were conducted at Sector 13- ID (GeoSoilEnviroCARS) at the Advance Photon Source at Argonne National Laboratory, Argonne, IL. Measurements were made of non-rhizosphere soil samples recovered from the U-contaminated wetland site. Approximately $100 \mathrm{mg}$ soil was pressed into a $6.3-\mathrm{mm}$ diameter disk pellet that was mounted in a custom made flow cell that was sealed with Kapton tape. The outlet and inlet tubing of gas flow cells were clamped with alligator clips to trap $\mathrm{N}_{2}$ in the sample holder during shipment and subsequent analysis. The storage ring operated at $7 \mathrm{GeV}$ $(120 \pm 5 \mathrm{~mA})$ in top-up mode. At Sector 13-ID, a liquid nitrogen cooled Si (111) double crystal monochromator was calibrated using $\mathrm{Y}$ metal foil $(17038 \mathrm{eV})$ and periodically verified during data collection to confirm stability. The samples were loaded into a Peltier-cooled cryostat system $\left(-18{ }^{\circ} \mathrm{C}\right)$ on an $\mathrm{x}-\mathrm{y}-\theta$ stepping-motor stage to minimize beam-induced artifacts. $\mu-\mathrm{XRF} \mathrm{U}$ and Fe maps $\left(1 \times 1 \mathrm{~mm}^{2}\right)$ were created by collecting spectra from $3-\mu \mathrm{m}$ steps at 0.05 second 
integrations. $\mathrm{U} \mathrm{L}_{3}$-edge $\mu$-XANES spectra were used to identify $\mathrm{U}$ oxidation state. $\mathrm{U}_{3}$-edge $\mu$ XANES spectra of hot spots and other areas were collected from 17,000 to 17,500 eV using 0.4 eV steps near the $\mathrm{U} \mathrm{L}_{3}$-edge $(17166 \mathrm{eV})$, and coarse $(2-5 \mathrm{eV})$ steps over the pre-edge and postedge regions.

Fe K-edge $\mu$-XANES data collection was conducted in a similar fashion. The $\mu$-XRF maps and $\mu$-XANES spectra were collected in fluorescence mode using a Vortex-ME4 four-element silicon drift detector. All the collected spectra were processed and analyzed using the IFEFFIT software package (Ravel and Newville, 2005). Data from multiple scans were processed by aligning and merging the spectra followed by background subtraction using the AUTOBK algorithm. Ferrous iron sulfate $\left(\mathrm{FeSO}_{4} \cdot 7 \mathrm{H}_{2} \mathrm{O}\right)$ and goethite cluster were used as standards for the Fe K-edge $\mu$-XANES analysis. Uranyl acetate $\left(\mathrm{UO}_{2}\left(\mathrm{CH}_{3} \mathrm{COO}\right)_{2} \cdot 2 \mathrm{H}_{2} \mathrm{O}\right)$ and uraninite $\left(\mathrm{U}_{3} \mathrm{O}_{8}\right)$ were used as standards for the $\mathrm{U} \mathrm{L}_{3}$-edge $\mu$-XANES.

\subsection{Microscopy}

Rhizosphere and non-rhizosphere subsamples from the Background location were analyzed for transmission electron microscopy (TEM), by suspending a portion of the subsamples in $\mathrm{dH}_{2} \mathrm{O}$ and then applying a 5- $\mu \mathrm{L}$ aqueous mixture to a TEM grid (formvar-carbon coated $200 \mathrm{Cu}$ mesh, Electron Microscopy Sciences, Hatfield, PA). Imaging and elemental analysis were done on a Tecnai T-12 (FEI), and a JEOL 2010 TEM (JEOL USA) instrument coupled with an energydispersive spectroscopy (EDS; Oxford). Scanning electron microscopy/energy dispersive spectroscopy (SEM/EDS; FEI Quanta 3D FE-FIB-SEM) was used to analyze the rhizosphere subsample from the \#1-Contaminated soil sample. These analyses were conducted to provide information about $U$ distribution in the plaque and rhizosphere and to assess whether the $U$ was associated with a specific type of mineral. An extensive survey of rhizosphere soil and Fe plaques was conducted in both secondary electron (SE) mode and back-scattered electron (BSE) mode. Helium ion microscopy (He-IM) was used to provide high-resolution images of the nanoparticles on plaques associated with roots recovered from the Background sample. As will be described below, the plaque particles were identified as those directly attached to the roots and which could not be readily separated from the roots (this will be discussed in more detailed in relation to Fig. 6). Compared to electron- or photon-, helium ion-beams have a smaller excitation volume and provide greater resolution $(\leq 0.35 \mathrm{~nm})$ on a wide range of materials. The samples were analyzed without any addition of conductive coatings, the beam size was $<0.1 \mathrm{~nm}$, and the main chamber pressure was $5 \times 10^{-7}$ Torr. (Table S1 in the Supporting Information provides a list of the various analyses conducted with each soil sample).

\section{Results and Discussion}

The characterization techniques used in this study probed different scales. The diffusion samplers probed tens of grams of (liquid) sample. The bulk soil chemistry (pH, XRD, CEC, Total Fe and Mn, DCB Fe and Mn, and U) probed grams of sample. Mössbauer spectroscopy probed bulk Fe mineralogy on milligrams of sample and the various microscopy techniques probed fractions of a milligram of sample (individual or groups of particles). As such, it was important to keep track of these various scales while integrating the results from these measurements.

\subsection{Study site geochemistry}


The bulk soil samples at the three locations were acidic ( $\mathrm{pH} 4.16$ to 5.47), contained high organic C concentrations (4.05 to $13.95 \mathrm{wt}-\%$ ), and their clay mineralogy was dominated by kaolinite and goethite, with lower concentrations of hematite and hydroxyl-interlayer vermiculite (Table 1). As is typical of wetland soils on the SRS (Dixon et al., 1997), the fines (clay and silt) percentages were relatively high compared to upland soils, between 21 and $54 \mathrm{wt}-\%$. SRS soils are naturally acidic (background $\mathrm{pH} \sim 5.5$ ) and unimpacted wetland soils are typically even more acidic ( $\mathrm{pH} ~ 4.8$; Dixon et al., 1997). As expected, the total U concentrations were much greater in the two contaminated soils, \#1-Contaminated (281 $\mathrm{mg} \mathrm{kg}^{-1}$ ) and \#2-Contaminated soil (189 $\left.\mathrm{mg} \mathrm{kg}^{-1}\right)$, than in the soil collected outside of the contamination area, the Background soil $(0.57$ $\mathrm{mg} \mathrm{kg}^{-1}$; Table 1 and Fig. 1). In the contaminated soils, greater than $79 \mathrm{wt}-\%$ of the U was extractable by the dithionite treatment, a strong reducing and citrate-complexing solution, suggesting that much of the $U$ was associated with Fe oxides or OM associated with Fe oxides. In the Background soil, only $9 \mathrm{wt}-\%$ of the $U$ was dithionite extractable, suggesting that the $U$ was much more strongly bound to the soil, likely within the crystalline soil-grain structure. Finally, the percentage of $U$ in porewater compared to that in the solid phase was very low $(<0.0003 \mathrm{wt}-\%)$, consistent with earlier reports that $\mathrm{U}$ binds extremely strongly to these soils under natural conditions (Barnett et al., 2002; Kaplan and Serkiz, 2001).

The porewater chemistry at the \#1-Contaminated and \#2-Contaminated locations were measured (Fig. 2). Uranium porewater concentrations ranged from 7 to $245 \mathrm{nM}$. In the \#1Contaminated profile, aqueous $U$ concentrations were greatest in the upper $20 \mathrm{~cm}$ depth (Fig. 2). Below the $20 \mathrm{~cm}$ depth, $U$ concentrations at both locations were more consistent, ranging from 7 to $67 \mathrm{nM}$. Over the entire profile, Eh ranged from mildly reducing $(\mathrm{Eh}=66 \mathrm{mV})$ to oxidizing $(\mathrm{Eh}=278 \mathrm{mV})$. Several parameters changed in manners consistent with expectations. Eh was positively correlated to porewater $U$ concentrations $(r=0.700, p \leq 0.001)$, which is consistent with the understanding that the oxidized form of $\mathrm{U}(\mathrm{VI})$ is more mobile and soluble than the reduced form of $\mathrm{U}(\mathrm{IV})$. Also, Eh was inversely correlated to dissolved $\mathrm{Fe}(\mathrm{r}=-0.416 ; \mathrm{p} \leq 0.01)$ and $\mathrm{Mn}(\mathrm{r}=-0.559 ; \mathrm{p} \leq 0.001)$ concentrations; consistent with the understanding that the reduced forms of $\mathrm{Fe}$ and $\mathrm{Mn}$ is more soluble than the oxidized form. $\mathrm{pH}$ had a limited range of 5.17 to 6.88 and was positively correlated to $U(r=0.418, p \leq 0.01)$ and inverse correlated to porewater Fe and Mn concentrations $(r=-0.575$ and -0.433 , respectively $\mathrm{p} \leq 0.01)$. The inverse relation between $\mathrm{pH}$ and dissolved $\mathrm{Mn}$ and Fe may be attributed to Mn and Fe sorbing more and precipitate more at the higher $\mathrm{pH}$ values at this study site. While DOC was very strongly correlated to Fe and Mn concentrations $(r=0.728$ and $r=0.629$, respectively, $p \leq 0.001)$, it was not correlated to U. Together, the trends in the U, Fe, Mn, and Eh data suggest that the more oxidizing conditions near the soil surface may influence the porewater chemistry of these parameters. Furthermore, the existence of this wide range of U concentrations through the 50$\mathrm{cm}$ depth profile and systematic changes with key aqueous solutes indicate that aqueous $\mathrm{U}$ concentrations varied in the ground at the centimeter scale, even though they were hydrologically connected. Uranium porewater concentrations were shown to be especially dependent on the geochemical conditions of microenvironments, presumably because of uranium's very strong interactions with porewater $\mathrm{pH}$, Eh, organic C, and carbonate levels (Miller et al., 2013). Seasonal porewater sampling is continuing and depth discrete soil analyses are being conducted to understand better the relationship between porewater chemistry and soil biogeochemical changes. 


\subsection{Mineralogy in the rhizosphere versus non-rhizosphere}

The rhizosphere and non-rhizosphere subsamples from the Background soil were characterized by Mössbauer spectroscopy, TEM, XCT, and He-IM. These measurements were made on this non-contaminated soil, instead of the two contaminated soil samples, to ease sample handling and minimize exposure to radioactivity. Mössbauer spectroscopy identified three major iron species: nanogoethite (nG), a poorly crystalline ferrihydrite-like phase (FHlike), and $\mathrm{Fe}(\mathrm{III})$ incorporated in the mineral phase (Clay Fe(III)) (Fig. 4; and modeled parameters of the $10 \mathrm{~K}$ spectra are presented in Table S2 ). Compared to the non-rhizosphere subsample, the rhizosphere had a significantly larger percentage of the ferrihydrite-like phase, $\sim 80 \%$ of the total Fe. The samples contained relatively little clay Fe, as evident from the relatively minor doublet peaks in the spectra. Assignment of the sextet peaks to nanogoethite and ferrihydrite-like phases were determined by qualitatively comparing spectra at various temperatures $(298,150,77,35$, and $10 \mathrm{~K}$, as described in Supporting Information and Fig. S1). The samples also contained very small amounts of hematite, based on incipient peaks in room temperature spectrum. Absence of distinct hematite peaks in below room temperature spectra may be due to the presence of OM coatings and $\mathrm{Al}$ substitution for Fe. Overall, comparison of rhizosphere and non-rhizosphere data also indicate that new minerals were not detected in the rhizosphere, but instead, the proportion of minerals differed (or the difference may be due to changes in the $\mathrm{OM} / \mathrm{Fe}$ ratio) (Eusterhues et al., 2008). Data modeling indicated unambiguously that the samples were free of Fe(II), which is generally consistent with wet chemistry measurements of the total soil, which indicated that there was between 1 and $2 \% \mathrm{Fe}$ (II) in the system (Table 1). Using indigenous plants (Phalaris arundinacea) recovered from a circumneutral $\mathrm{pH}$ wetland, Hansel et al. (2001) reported that the plaques were composed predominantly of ferrihydrite (63\%) with lesser amounts of goethite (32\%) and minor levels of siderite (5\%). This mineral composition is somewhat similar to that reported here; the presence of siderite in the samples examined by Hansel et al. (2001) can be attributed to their higher $\mathrm{pH}$ environment than exists at the study site. To put these results into context, there is unfortunately no other $\mathrm{Fe}$ oxidation state measurements made in these wetlands. Soil cores collected from near the diffusion samplers reveled limited zones of dark gray, indicative of the presence of $\mathrm{Fe}(\mathrm{II})$. Furthermore, the elevated dissolved Fe concentrations noted from the diffusion samplers, is also indicated that Fe(II) likely exists at lower depths, $<30 \mathrm{~cm}$ depth (Figure 3). Iron mineralogy in a SRS vadose zone sediments also indicated that no Fe(II) was present, and that $25-30 \%$ of the iron in the system was hematite, $60-65 \%$ was nano Al-goethite, and $<10 \%$ was $\mathrm{Fe}$ (III) in phyllosilicates (Hixon et al., 2010).

\subsection{Particle morphology in the rhizosphere versus non-rhizosphere}

TEM images were collected at low magnification of the root and surrounding soil (Fig. 5A) and at greater magnification of brown areas, presumable to be the non-rhizosphere (Fig. 5B), and the red areas, presumed to be the rhizosphere (Fig. 5C). The brown samples were composed primarily of particles with two distinct morphologies: larger hexagonal plate-like-crystals and smaller needle-shaped crystals (Fig. 5B). In the red soil near the root, the same two distinct particle morphologies were evident, except there were many more of the needle-shaped crystals and there were an abundance of much smaller secondary crystalline products that covered the needles (Fig. 5C insert). Based on the Mössbauer results, it is possible that these needle-shaped 
crystals were a combination of the nanogoethite (nG1) and the ferrihydrite-like (FH-like) phases (Fig. 4; Fig. S1). The larger plate-like crystals are likely hematite, which is frequently reported in these soils (Kaplan et al., 2011), was detectable by XRD in some of the bulk soils (Table 1), and also identified by Mössbauer spectroscopy (Fig. 4). Again, there was an insufficient amount of the clay-size fraction from the rhizosphere subsample to conduct XRD.

\subsection{Mineral morphology in the root plaque environment}

Particle morphology of plaque samples recovered from the \#1-Contaminated location was evaluated using XCT and He-IM (Fig. 6). These techniques were selected to provide information about the plaques at the nanometer scale (He-IM) and the millimeter scale (XCT). XCT scans were compiled to generate longitudinal and cross-sectional images of two roots growing through a clump of soil particles (Fig. 6A and Fig. 6C). The roots had a diameter of $\sim 0.5 \mathrm{~mm}$ and the clump of soil was $\sim 2-\mathrm{mm}$ wide. The plaque located at the root/soil interface was composed of a thin layer of highly oriented particles. While it is difficult to ascertain the thickness in the plaque from these image, other images compiled at greater magnification, suggest the plaque was $<10 \mu \mathrm{m}$ thick. Growing Typha latifolia L. under hydroponic conditions, Taylor et al. (1984) reported that plaque thickness extended as much as 15 to $17 \mu \mathrm{m}$ and depended greatly on $\mathrm{pH}$ and $\mathrm{Fe}^{2+}(a q)$ concentrations.

At the sub-micron scale, He-IM images showed that the plaque was composed primarily of highly oriented particles and to a lesser extent of larger hexagonal plates (Fig. 6B). The smaller particles were oriented not only parallel to the surface of the roots as indicated by the XCT, but also oriented end-to-end along the longitudinal axis of the root. Such conformity to the roots' morphology suggests that the roots were involved either directly or indirectly in the biogeochemical conditions conducive to the nanoparticle formation; perhaps by providing a surface that promoted heterogeneous precipitation, or a redox gradient that promoted homogenous Fe-oxyhr(oxide) precipitation. Using SEM, Taylor et al. (1984) reported two types of minerals on plaques, amorphous and particle, and did not note any particle orientation with the root surface. Taylor et al. (1984) may not have observed orientation because of lower resolution offered by SEM compared to He-IM.

\subsection{Uranium oxidation state and distribution}

Iron and uranium $\mu$-XANES and $\mu$-XRF analyses were conducted on the non-rhizosphere Ucontaminated wetland soil sample (Fig. 7). There was insufficient sample mass to conduct similar measurements on the rhizosphere subsample. $\mu$-XRF mapping indicated that, not surprisingly, Fe covered much of the soil surfaces (Fig. 7A). Dozens of Fe K-edge $\mu$-XANES spectra were collected and showed that the Fe existed almost exclusively in the +3 oxidation state (an example of these spectra are presented in Fig. 7C). This is consistent with the Mössbauer data (Fig. 4). $\mu$-XRF mapping of $U$ indicated that $U$ was much more heterogeneously distributed than Fe (Fig. 7B). Spot $\mathrm{U} \mathrm{L}_{3}$-edge $\mu$-XANES measurements indicated that the $U$ existed primarily as $\mathrm{U}(\mathrm{VI})$ (Fig. 7D). The predominance of $U$ in the +6 oxidation state in these wetland soils is consistent with previous measurements by Li et al. (2015) and Bertsch et al. (1994). These other researchers also showed that the uranyl in these soils was primarily bound to natural organic matter. 
Uranium-mineral associations in the rhizosphere of a Juncus sp. root recovered from the \#1Contaminated location were evaluated by SEM/EDS (Fig. 8). SEM was operated in secondary electron imaging mode (Fig. 8A) and back-scattering electron mode (Fig. 8B). Secondary electron imaging mode provided clear images of the particle morphologies, while in the same spectroscopic field the back-scattering electron mode provided elemental information, such that brighter particles are indicative of materials consisting of heavier elements.

While the \#1-Contaminated sample had elevated U concentrations (281 mg kg${ }^{-1} \mathrm{U}$; Table 1), the rhizosphere and the non-rhizosphere sub-samples of this soil could not be detected by SEM/EDS, which has a detection limit of $\sim 1000 \mathrm{mg} \mathrm{kg}^{-1} \mathrm{U}$. However, the $\mathrm{U}$ concentrations associated with the plaques were detectable, albeit they required long instrumental collection times of >200-s. Of the 63 EDS spectra collected of the plaques, 21 contained detectable U peaks. The strongest elemental coincidence with $\mathrm{U}$ was with $\mathrm{P}$ (Fig. 8D). In all 21 spectra containing U peaks, a P peak was also identified. Any spectra that did not have a P peak did not have a U peak (Fig. 8C), but not all spectra with P contained U. In a mesocosm study using SRS samples and millimolar concentrations of uranyl (as opposed to sub-micromolar concentrations that existed in this study), Chang et al. (2014) showed a strong correlation between P and U concentrations on plaques using SEM/EDS. Similarly, Fomina et al. (2008) reported that uranyl released from depleted uranium ammunition tended to form U-O-P bonds on fungal mycelium, while nearby crystalline precipitates were composed of meta-autunite-type minerals $\left(\mathrm{CaU}_{2} \mathrm{P}_{2} \mathrm{O}_{12-}\right.$ $\left.8 \mathrm{H}_{2} \mathrm{O}\right)$, uramphite $\left(\mathrm{NH}_{4}\left(\mathrm{UO}_{2}\right)\left(\mathrm{PO}_{4}\right) 3 \mathrm{H}_{2} \mathrm{O}\right)$ and/or chernikovite $\left(\mathrm{H}_{2}\left(\mathrm{UO}_{2}\right)_{2}\left(\mathrm{PO}_{4}\right)_{2} \cdot 8 \mathrm{H}_{2} \mathrm{O}\right)$. Based on NanoSIMS and TEM analyses, Misson et al. (2009) reported that $\mathrm{U}$ and $\mathrm{P}$ formed precipitates within Arabidopsis thaliana.

Essentially all EDS spectra included sizable $\mathrm{C}, \mathrm{Fe}$, and Mn peaks, consistent with current understanding of plaque composition (Batty et al., 2000). Citrate-dithionite-bicarbonate (CDB) extraction of the bulk soil (Table 1) indicating a large amount of Mn, which likely existed as Mnsubstituted Fe oxyhydroxide rather than as pure mineral phases (Hu et al., 2010). Organic C is enriched in the rhizosphere and especially in plaques due to the constant recycling of root material, root exudates, and C that originates from rhizosphere microbes (Jones, 1998). The few spectra that did not include large amounts of $\mathrm{Fe}$ or Mn, also did not include $\mathrm{U}$ : these spectra were dominated by Si peaks, $\mathrm{Al}$ and Si peaks, or Ti peaks.

\section{Conclusions}

Uranium in a contaminated wetland soil existed primarily in a dithionite-extractable fraction (>79 wt-\%), likely in associating with soil coatings. A very small, but important fraction $\left(10^{-3}\right.$ $\mathrm{wt}-\%)$ of the $\mathrm{U}$ existed in the porewater at sub- $\mu \mathrm{M}$ concentrations. Porewater $\mathrm{U}$ concentrations in the wetland generally varied in a systematic manner in the centimeter scale with other aqueous porewater constituents (e.g. pH, Eh, Mn, Fe, and DOC). The $\mu$-XANES analysis of the bulk soil in this wetland system showed that the $U$ existed almost exclusively in the +6 oxidation state. Due to detection limits, spectroscopic investigations of the rhizosphere soils could not confirm $\mathrm{U}$ enrichment in the rhizosphere as previously observed (Jaffé et al., 2014; Kim et al., 2003), but confirmed enrichment in the plaques. Occurrence of $\mathrm{U}$ was closely related to that of $\mathrm{P}$ on plaques. This result adds to the growing body of evidence indicating that $\mathrm{P}$ plays an important role in $\mathrm{U}$ geochemistry in micro-environments influenced by biological systems (Chang et al., 2014; Fomina et al., 2008; Misson et al., 2009). 
The findings from this research largely supported our hypothesis and provide a new

perspective of the geochemical processes responsible for the observed enrichment of $\mathrm{U}$ in wetlands. It showed that wetland plant roots can create an environment in the rhizosphere that is conducive to the formation of $\mathrm{Fe}$ (III)-(oxyhydro)oxides that may contribute to the $\mathrm{U}$ enrichment in the rhizosphere. The relative proportion and the morphology of the minerals differed between the rhizosphere and non-rhizosphere soil fractions. Mössbauer spectroscopy showed an enrichment of nanogoethite particles and ferrihydrite-like phases in the rhizosphere. He-IM and TEM images supported the conclusion that nanoparticles were enriched near the roots. In addition to these mineralogical differences, the plaque particles were highly oriented. XCT showed that the plaques were $\sim 10 \mu \mathrm{m}$ thick and continuous throughout most of the root. He-IM showed the plaques were primarily composed of nanoparticles, tens of nanometers in size, which were oriented in an end-to-end manner along the axis of the root. A biogeochemical process that would explain the enrichment of Fe-nanoparticles in the rhizosphere is that porewater Fe(II) from wetland entered the more oxidized, and microbe- and organic matter-rich rhizosphere and then precipitated as $\mathrm{Fe}$ (III) phases. The enhanced orientation of the plaque Fe nanoparticles may have resulted from the geochemical conditions promoted by the root. The enrichment of such highly reactive Fe-nanoparticles in the rhizosphere and on plaques is likely a contributing factor responsible for the concentrating of contaminants in wetlands.

\section{Acknowledgements}

This work was supported by the Subsurface Biogeochemistry Research Program within the Office of Biological and Environmental Research (OBER), Office of Science, U.S. Department of Energy, Grants DR-FG02-08ER64567 and ER65222-1038426-0017532. Mössbauer spectroscopy, XCT, TEM, He-IM, and SEM/EDS were conducted at EMSL, a national scientific user facility sponsored by DOE's OBER program. EMSL is located at the PNNL in Richland, WA, USA. Use of Advance Photon Source was supported by the U.S. DOE Office of Science, Office of Basic Energy Sciences, under contract No. W-31-109-ENG-38. Work was conducted at Princeton University under the U.S. Department of Energy Contract DE-SC0006847. Although EPA contributed to this article, the research presented was not directly performed by or funded by EPA and was not subject to EPA's quality system requirements. Consequently, the views, interpretations, and conclusions expressed in this article are solely those of the authors and do not necessarily reflect or represent EPA's views or policies. 


\section{References}

Bacha RE, Hossner LR. Characteristics of coatings formed on rice roots as affected by iron and manganese additions. Soil Science Society of America Journal 1977; 41: 931-935.

Barnett MO, Jardine PM, Brooks SC. U(VI) adsorption to heterogeneous subsurface media: Application of a surface complexation model. Environmental Science and Technology 2002; 36: 937-942.

Batty LC, Baker AJM, Wheeler BD, Curtis CD. The effect of $\mathrm{pH}$ and plaque on the uptake of $\mathrm{Cu}$ and $\mathrm{Mn}$ in Phragmites australis (Cav.) Trin ex. Steudel. Annals of Botany 2000; 86: 647-653.

Bertsch PM, Hunter DB, Sutton SR, Bajt S, Rivers ML. In situ chemical speciation of uraniumin soils and sediments by micro X-ray absorption spectroscopy. Environmental Science and Technology 1994; 28: 980-984.

Bowden WB. The biogeochemsitry of nitrogen in fresh-water wetlands. Biogeochemistry 1987; 4: 313348.

Bronick CJ, Lal R. Soil structure and management: a review. Geoderma 2005; 124: 3-22.

Chang H-S, Buettner SW, Seaman JC, Jaffé PR, Koster van Groos PG, Li D, et al. Uranium immobilization in an iron-rich rhizosphere of a native wetland plant from the Savannah River Site under reducing conditions. Environ. Sci. Technol 2014; 48: 9270-9278.

Chen CC, Dixon JB, Turner FT. Iron coatings on rice roots: Morphology and models of development. Soil Science Society of America Journal 1980; 44: 1113-1119.

Crowder AA, Macfie SM. Seasonal deposition of ferric hydroxide plaque on roots of wetland plants. Canadian Journal of Botany-Revue Canadienne De Botanique 1986; 64: 2120-2124.

Dixon KL, Rogers VA, Conner SP, Cummings CL, Gladden JB, Weber JM. Geochemical and Physical Properties of Wetland Soils at the Savannah River Site, Westinghouse Savannah River Company, Aiken, SC, 1997.

Emerson D, Weiss JV, Megonigal JP. Iron-oxidizing bacteria are associated with ferric hydroxide precipitates (Fe-plaque) on the roots of the wetland plants. Applied Environmental Microbiology 1999; 65: 2758-2761.

Eusterhues K, Wagner FE, Häusler W, Hanzlik M, Knicker H, Totsche KU, et al. Characterization of ferrihydrite-soil organic matter coprecipitates by X-ray diffraction and Mossbauer spectroscopy. Environmental Science \& Technology 2008; 42: 7891-7897.

Evans AG, Bauer LR, Haselow JS, Hayes DW, Martin HL, McDowell WL, et al. Uranium in the Savannah River Site environment. Westinghouse Savannah River Company, Aiken, SC, 1992.

Fomina M, Charnock JM, Hillier S, Alvarez R, Livens F, Gadd GM. Role of fungi in the biogeochemical fate of depleted uranium. Current Biology 2008; 18: R375-R377.

Frohne T, Rinklebe J, Diaz-Bone RA. Contamination of floodplain soils along theWupper River, Germany, with $\mathrm{As}, \mathrm{Co}, \mathrm{Cu}, \mathrm{Ni}, \mathrm{Sb}$, and $\mathrm{Zn}$ and the impact of pre-definite redox variations on the mobility of these elements. Soil \& Sediment Contamination 2014; 23: 779-799.

Gibberd MR, Gray JD, Cocks PS, Comer TD. Waterlogging tolerance among a diverse range of Tifolium accessions is related to root porosity, lateral root formation and aerotropic rooting. Annuals of Botany 2001; 88: 579-589.

Green MS, Etherington JR. Oxidation of ferrous iron by rice (Oryza sativa L.) roots - Mechanism for waterlogging tolerance. Journal of Experimental Botany 1977; 28: 678-\&.

Grybos M, Davranche M, Gruau G, Petitjean P. Is trace metal release in wetland soils controlled by organic matter mobility or Fe-oxyhydroxides reduction? Journal of Colloid and Interface Science 2007; 314: 490-501.

Hansel CM, Fendorf S, Sutton S, Newville M. Characterization of Fe plaque and associated metals on the roots of mine-waste impacted aquatic plants. Environmental Science and Technology 2001; 35: 3863-3868. 
Hixon AE, Hu YJ, Kaplan DI, Kukkadapu RK, Nitsche H, Qafoku O, et al. Influence of iron redox transformations on plutonium sorption to sediments. Radiochimica Acta 2010; 98: 685-692.

Hu YJ, Schwaiger LK, Booth CH, Kukkadapu RK, Cristiano E, Kaplan D, et al. Molecular interactions of plutonium(VI) with synthetic manganese-substituted goethite. Radiochimica Acta 2010; 98: 655663.

Jaffé PR, Chang HS, Gilson E, Kaplan DI, Li D, Groos PKv, et al. Fate of uranium during transport across the groundwater-surface water interface. Terrestrial Ecosystem Science - Subsurface Biogeochemistry Research PI's Meeting. . U. S. Department of Energy, Washington, DC, 2014, pp. 77.

James RV, Rubin J. Transport of chloride ion in a water-unsaturated soil exhibiting anion exclusion. Soil Science Soceityof America Journal 1986; 50: 1142-1149.

Johnston CA. Sediment and nutrient retention by fresh-water wetlands - Effects on surface-water quality. Critical Reviews in Environmental Control 1991; 21: 491-565.

Jones DL. Organic acids in the rhizosphere-a critical review. Plant and Soil 1998; 205: 25-44.

Kaplan DI, Roberts KA, Schwehr KA, Lilley MS, Brinkmeyer R, Denham ME, et al. Evaluation of a radioiodine plume increasing in concentration at the Savannah River Site. Environmental Science \& Technology 2011; 45: 489-495.

Kaplan DI, Serkiz SM. Quantification of thorium and uranium sorption to contaminated sediments J. Radioanalytical and Nuclear Chemistry 2001; 248: 529-535.

Kaplan DI, Xu C, Huang S, Lin Y, Tolić N, Roscioli-Johnson KM, et al. Unique Organic Matter and Microbial Properties in the Rhizosphere of a Wetland Soil. Environmental Science \& Technology 2016; 50: 4169-4177.

Kaplan DI, Zhang S, Roberts KA, Schwehr K, Xu C, Creeley D, et al. Radioiodine concentrated in a wetland. Journal of Environmental Radioactivity 2013; 131: 57-61.

Kelly S, Wu W-M, Yang F, Criddle CS, Marsh TL, O'Loughlin E, et al. Uranium transformations in static microscosms. Environ. Sci. \& Technol 2010; 44: 236-242.

Kelly SD, Kemner KM, Carley J, Criddle CS, Jardine PM, Marsh TL, et al. Speciation of uranium in sediments before and after in situ biostimulation. Environmental Science and Technology 2008; 42: 1558-1564.

Kennish MJ. Environmental threats and environmental future of estuaries. Environmental Conservation 2002; 29: 78-107.

Kim S, Kramer RW, Hatcher PG. Graphical method for analysis of ultrahigh-resolution broadband mass spectra of natural organic matter, the van Krevelen diagram. Analytical Chemistry 2003; 75 : 5336-5344.

King GM, Garey MA. Ferric iron reduction by bacteria associated with the roots of freshwater and marine macrophytes. Applied Environmental Microbiology 1999; 65: 4393-4398.

Langmuir D. Uranium solution-mineral equilibria at low temperatures with applications to sedimentary ore deposits. Geochimica et Cosmochimica Acta 1978; 42: 547-569.

Li D, Seaman JC, Chang HS, Jaffé P, Groos PKv, Jiang DT, et al. Retention and chemical speciation of uranium in an oxidized wetand sediment from the Savannah River Site. Journal of Environmental Radioactivity 2015; 131: 40-46.

Lovley DR. Microbial Fe (III) reduction in subsurface environments. FEMS Microbiology Reviews 1997; 20: 305-313.

MacDonald LH, Paull JS, Jaffé PR. Enhanced semipermanent dialysis samplers for long-term environmental monitoring in saturated sediments. Environmental Monitoring and Assessment 2013; 185: 3613-3624.

Mendelssohn IA, Postek MT. Elemental analysis of deposits on the roots of Spartina alterniflora Loissel. American Journal of Botany 1982; 69: 904-912. 
Menhelssohn IA. Factors Controlling the Formation of Oxidized Root Channels: A Review and Annotated Bibliography, US Army Corps of Engineers, Baton Rouge, LA, 1993.

Miller AW, Rodriguez DR, Honeyman BD. Simplified behaviors from increased heterogeneity: I. 2-D uranium transport experiments at the decimeter scale. Journal of Contaminant Hydrology 2013; 148: 39-50.

Misson J, Henner P, Morello M, Floriani M, Wu T-D, Guerquin-Kern J-L, et al. Use of phosphate to avoid uranium toxicity in Arabidopsis thaliana leads to alterations of morphological and physiological responses regulated by phosphate availability. Environmental and Experimental Botany 2009; 67: 353-362.

O'Geen AT, Budd R, Gan J, Maynard JJ, Parikh SJ, Dahlgren RA. Mitigating nonpoint source pollution in agriculture with constructed and restored wetlands. In: Sparks DL, editor. Advances in Agronomy, Vol 108. 108, 2010, pp. 1-76.

Otte ML, Rozema J, Koster L, Haarsma MS, Broekman RA. Iron plaque on roots of Aster tripolium L. interaction with zinc uptake. New Phytologist 1989; 111: 309-317.

Pickett JB. Heavy metal contamination in Tims Branch sediments, Westinghouse Savannah River Company, Aiken, SC, 1990.

Ravel B, Newville M. Athena, Artemis, Hephaestus: data analysis for X-ray absorption spectroscopy using IFEFFIT. Journal of Synchrotron Radiation 2005; 12: 537-541.

Schlesinger WH. On the fate of anthropogenic nitrogen. Proceedings of the National Academy of Sciences of the United States of America 2009; 106: 203-208.

Singh A, Catalono JG, Ulrich DU, Giammar DE. Molecular-scale structure of uranium(VI) immobilized with goethite and phosphate. Environmental Science and Technology 2012; 46: 6594-6603.

Singh A, Ulrich KU, Giammar DE. Impact of phosphate on $\mathrm{U}(\mathrm{VI})$ immobilization in the presence of goethite. Geochim. Cosmochim. Acta 2010; 74: 6324-6343.

Sowder AG, Bertsch PM, Morris PJ. Partitioning and Availability of Uranium and Nickel in Contaminated Riparian Sediments. Journal of Environmental Quality 2005; 32: 885-898.

Sparks DL. Methods of Soil Analysis, Part 3 - Chemical Methods. Soil Science Society of America, Inc.: Madison, WI, 1996.

Sposito G. Electron shuttling by natural organic matter: Twenty years after. Aquatic Redox Chemistry. 1071. American Chemical Society, 2011, pp. 113-127.

St-Cyr L, Crowder AL. Manganese and copper in the root plaque of Phragmites australis (Cav.) Trin. Ex Steudel. Soil Science 1990; 149: 191-198.

Taylor GJ, Crowder AA, Rodden R. Formation and morphology of an iron plaque on the roots of Typha latifolia L. grown in solution culture. American Journal of Botany 1984; 71: 666-675.

Thomas AL, Guerreino MC, Sodek L. Aerenchyma formation and recovery from hypoxia of the flooded root system of nodulated soybean. Annuals of Botany 2005; 96: 1191-1198.

Turick CE, Knox AS, Leverette CL, Kritzas YG. In situ uranium stabilization by microbial metabolites. Journal of Environmental Radioactivity 2008; 99: 890-899.

Wall JD, Krumholz LR. Uranium reduction. Annu. Rev. Microbiol. 2006; 60: 149-166.

Wang TG, Peverly JH. Iron oxidation states on root surfaces of a wetland plant (Phragmites australis). Soil Science Society of America Journal 1999; 63: 247-252.

Wang Y, Bagnoud A, Suvorova E, McGivney E, Chesaux L, Phrommavanh V, et al. Geochemical control on uranium(IV) mobility in a mining-impacted wetland. Environmental Science \& Technology 2014; 48: 10062-10070.

Wang Y, Frutschi M, Suvorova E, Phrommavanh V, Descostes M, Osman AAA, et al. Mobile uranium(IV)bearing colloids in a mining-impacted wetland. Nature Communications 2013; 4: 1-9. 
Table 1. Bulk soil characterization ( $n=2$ or 3; sample locations identified in Fig. 1).

\begin{tabular}{|c|c|c|c|}
\hline Parameter (unit) & \#1-Contaminated & \#2-Contaminated & Background \\
\hline $\mathrm{pH}$ & 5.47 & 4.97 & 4.16 \\
\hline Sand/Silt/Clay (wt-\%) & $68 / 3 / 29$ & $36 / 18 / 46$ & $79 / 14 / 6$ \\
\hline Total C (wt-\%) & 4.05 & 3.95 & 13.95 \\
\hline Total N (wt-\%) & 0.16 & 0.21 & 0.55 \\
\hline Total S (wt-\%) & 0.02 & 0.05 & 0.07 \\
\hline $\operatorname{CEC}\left(\operatorname{meq}(100 \mathrm{~g})^{-1}\right)$ & 3.89 & 4.17 & 4.75 \\
\hline Total Fe $\left(\mathrm{mg} \mathrm{kg}^{-1}\right)$ & 11971 & 10818 & 2635 \\
\hline CDB-extractable $\mathrm{Fe}\left(\mathrm{mg} \mathrm{kg}^{-1}\right)$ & 5104 & 4547 & 1324 \\
\hline $\mathrm{Fe}(\mathrm{II}): \mathrm{Fe}(\mathrm{III})$ & 0.02 & 0.01 & NA \\
\hline Total Mn $\left(\mathrm{mg} \mathrm{kg}^{-1}\right)$ & 117 & 124 & 84.3 \\
\hline Dithionite $\mathrm{Mn}\left(\mathrm{mg} \mathrm{kg}^{-1}\right)$ & 39.8 & 48.4 & 28.7 \\
\hline $\begin{array}{l}\text { XRD mineralogy } \\
(<2-\mu m \text { clay fraction })^{a}\end{array}$ & $\begin{array}{l}\text { Kao }>\text { HIV }>\text { qtz }> \\
\text { goeth }>\text { gib }>\text { rutile }\end{array}$ & $\begin{array}{c}\text { Kao > goeth > HIV } \\
1.4 \mathrm{~nm}(\text { no qtz })\end{array}$ & $\begin{array}{l}\text { Kao }>\text { goeth }>\text { hem } \\
(\text { no qtz or } 1.4 \mathrm{~nm})\end{array}$ \\
\hline Total U (mg kg-1) & 281 & 189 & 0.57 \\
\hline CDB-extractable $\mathrm{U}\left(\mathrm{mg} \mathrm{kg}^{-1}\right)$ & 259 & 149 & 0.05 \\
\hline Structural U (wt-\%) & 8 & 21 & 91 \\
\hline CDB-extractable $\mathrm{U}(\text { wt- } \%)^{\mathrm{b}}$ & 92 & 79 & 9 \\
\hline Porewater U (wt-\%) ${ }^{\mathrm{b}}$ & 0.00057 & 0.00034 & $<0.00003$ \\
\hline \multicolumn{4}{|c|}{ 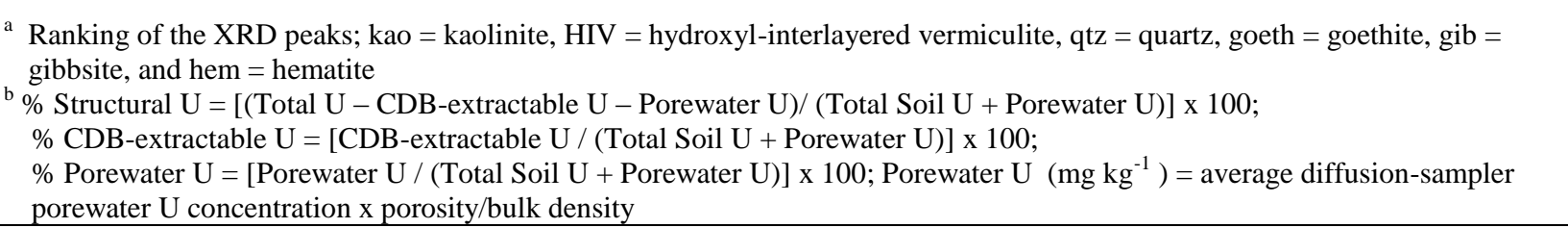 } \\
\hline
\end{tabular}




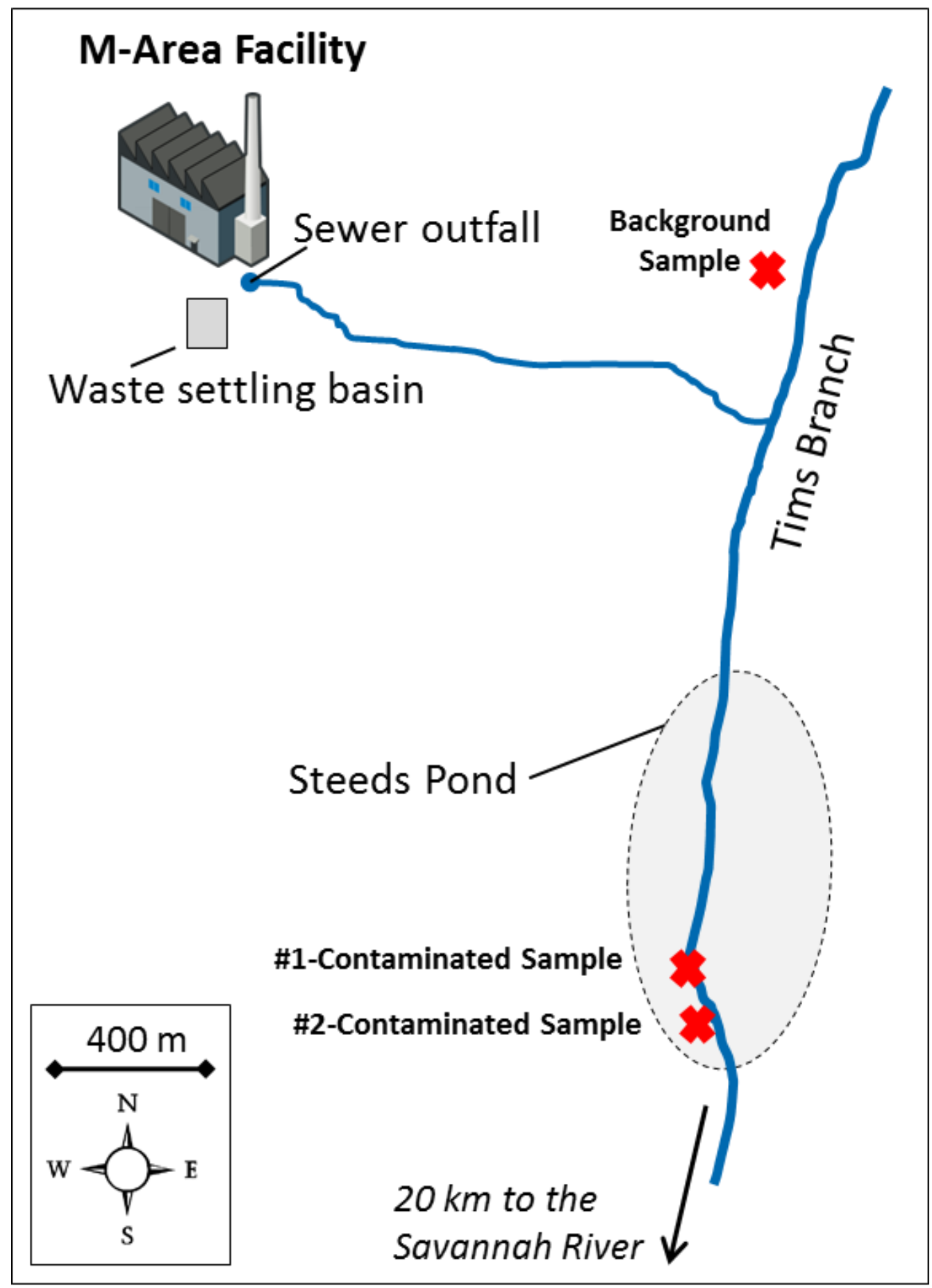

Fig. 1. Schematic of Tims Branch study site, locating the former MArea nuclear materials processing facility, Steeds Pond, the two contaminated sample sites (\#1 and \#2), and the less contaminated sample (Background). (Approximate distances are provided). 


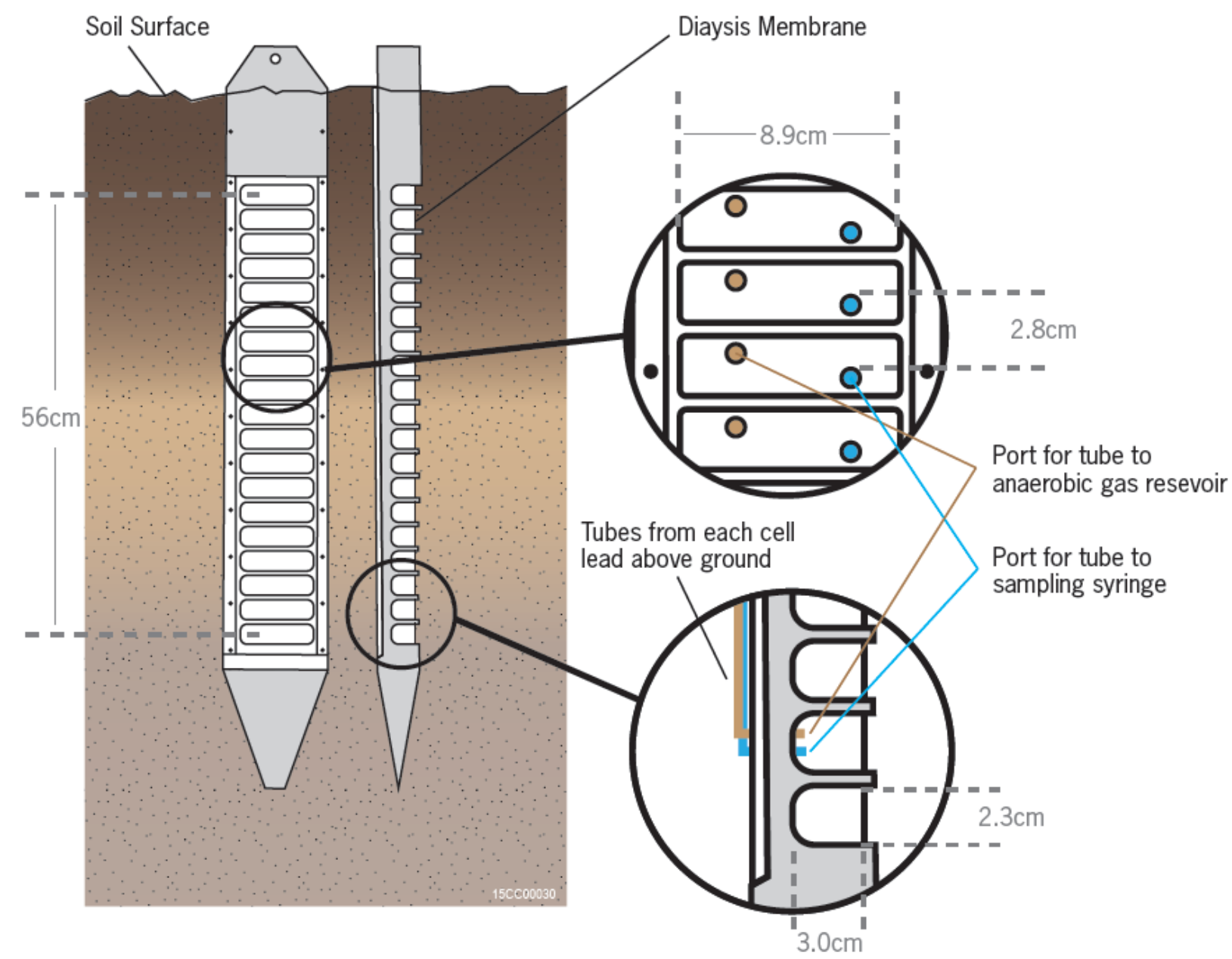

Fig. 2. Schematic of front, side and close up of the diffusion sampler. At the bottom right, a close up of the chambers reveals how two Tygon tubes connect to each chamber. During sampling, one tube is connected to an inert atmosphere and the second tube is used to withdraw the aqueous sample. Diffusion samplers were installed at the \#1- and \#2Contaminated locations. 

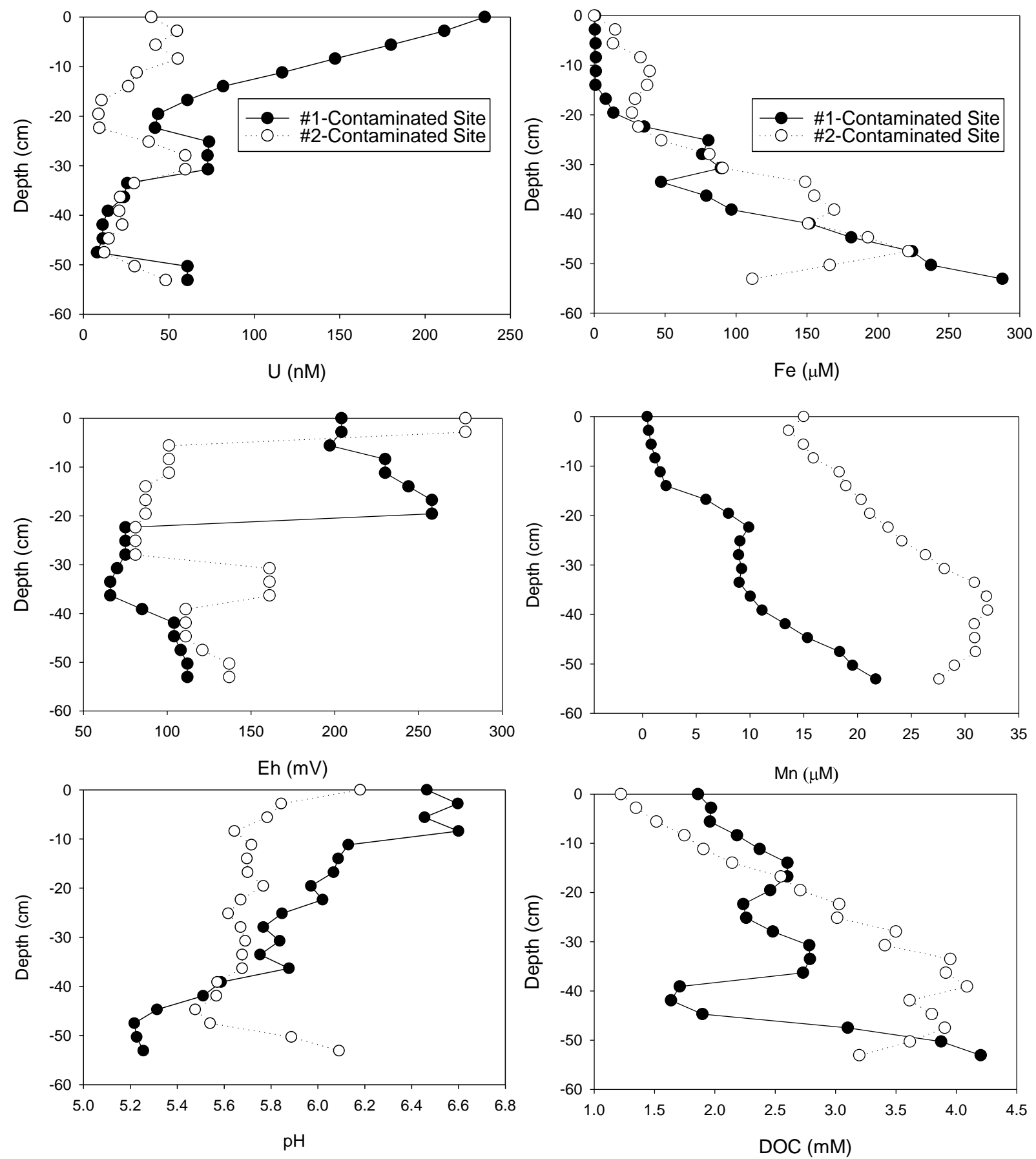

Fig. 3. Chemistry of porewater recovered from diffusion samplers located at \#1Contamininated and \#2-Contaminated locations (see map in Fig. 1). 

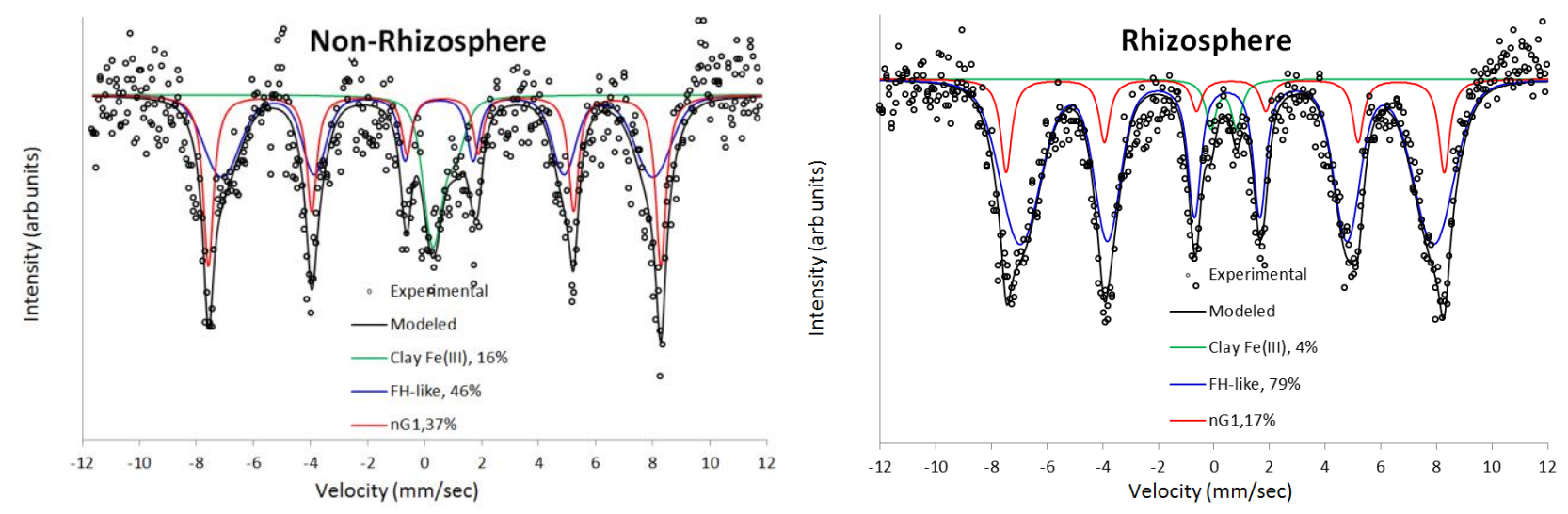

Fig. 4. Mössbauer spectra at $10{ }^{\circ} \mathrm{K}$ of the non-rhizosphere and rhizosphere subsamples from the Background soil (Fig. 1). (Clay Fe(III) = Fe(III) in clay mineral structures; FHlike $=$ ferrihydrite-like phases; $\mathbf{n G 1}=$ nanogoethite phase $)$. 

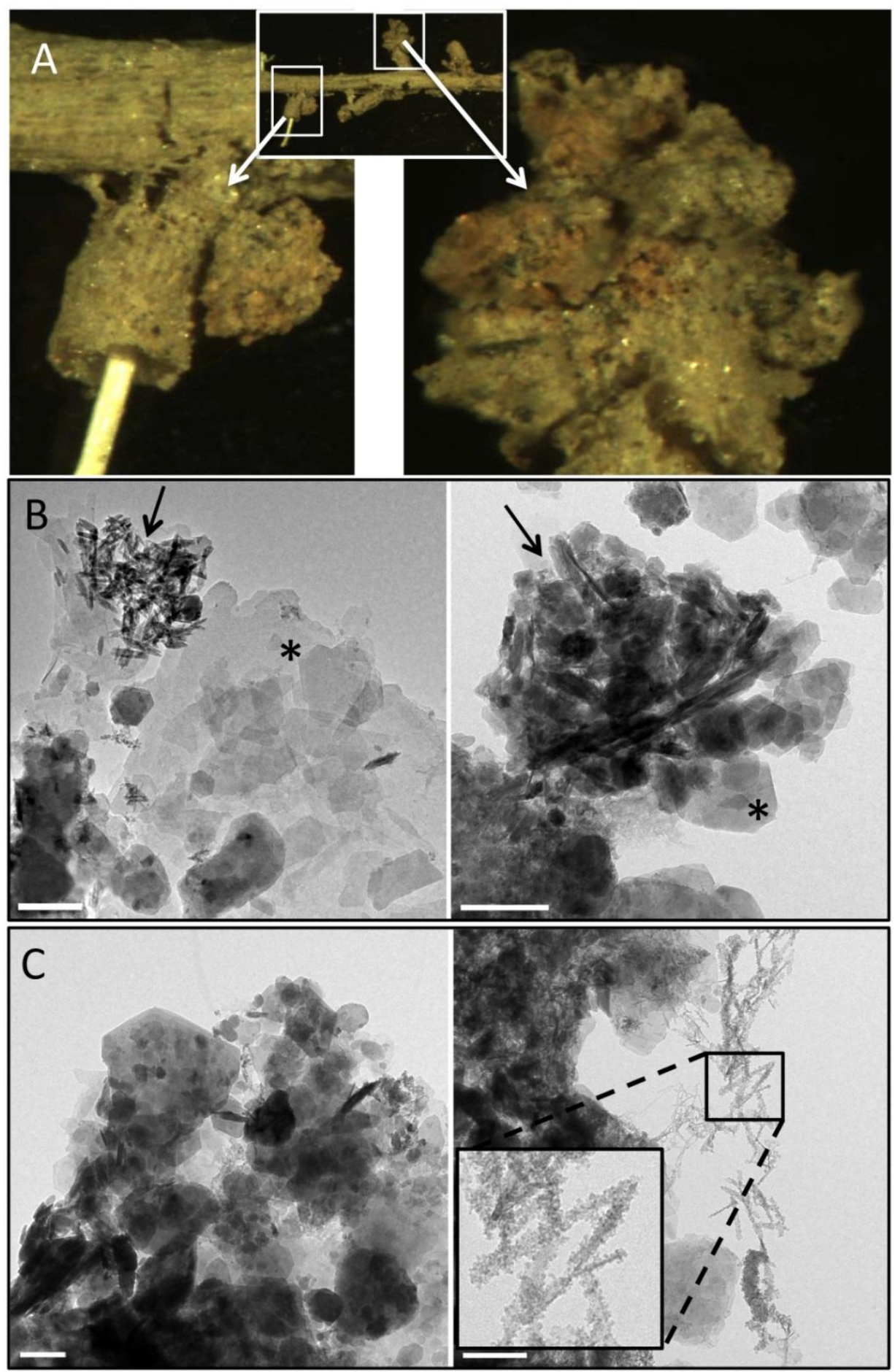

Fig. 5. TEM images at multiple magnifications from the Background soil of (A) a clump of soil associated with a root (Juncus sp.; smaller image) and two larger close up images showing the red rhizosphere and brown non-rhizosphere soil; (B) close up images of the non-rhizosphere region, showing the two primary morphologies: larger hexagonal plate-like structures (asterisk) and smaller needle-shaped structures (arrows); (C) close up of the red region, showing the same two primary morphologies observed in the non-rhizosphere, except there were more needle-shaped structures, many of which included nano-crystalline products (insert). Scale bars are $200 \mathrm{~nm}$. 


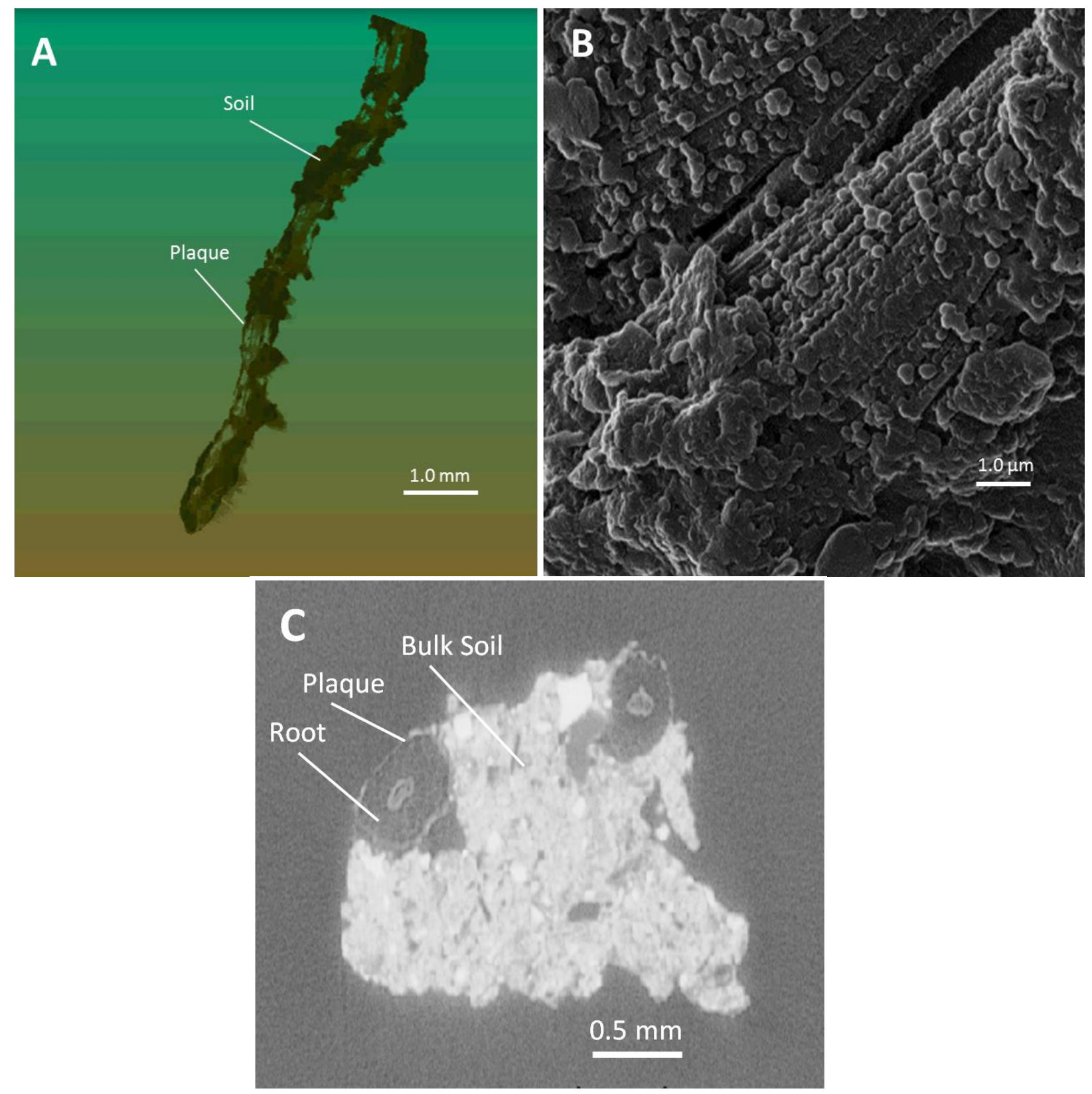

Fig. 6. Images of Juncus sp. root plaques recovered from the Background wetland location. (A) XCT longitudinal image, (C) He-IM image of a plaque showing the two primary mineral morphologies, the hexagonal plates and nanoparticles, and (C) XCT cross-sectional image. 

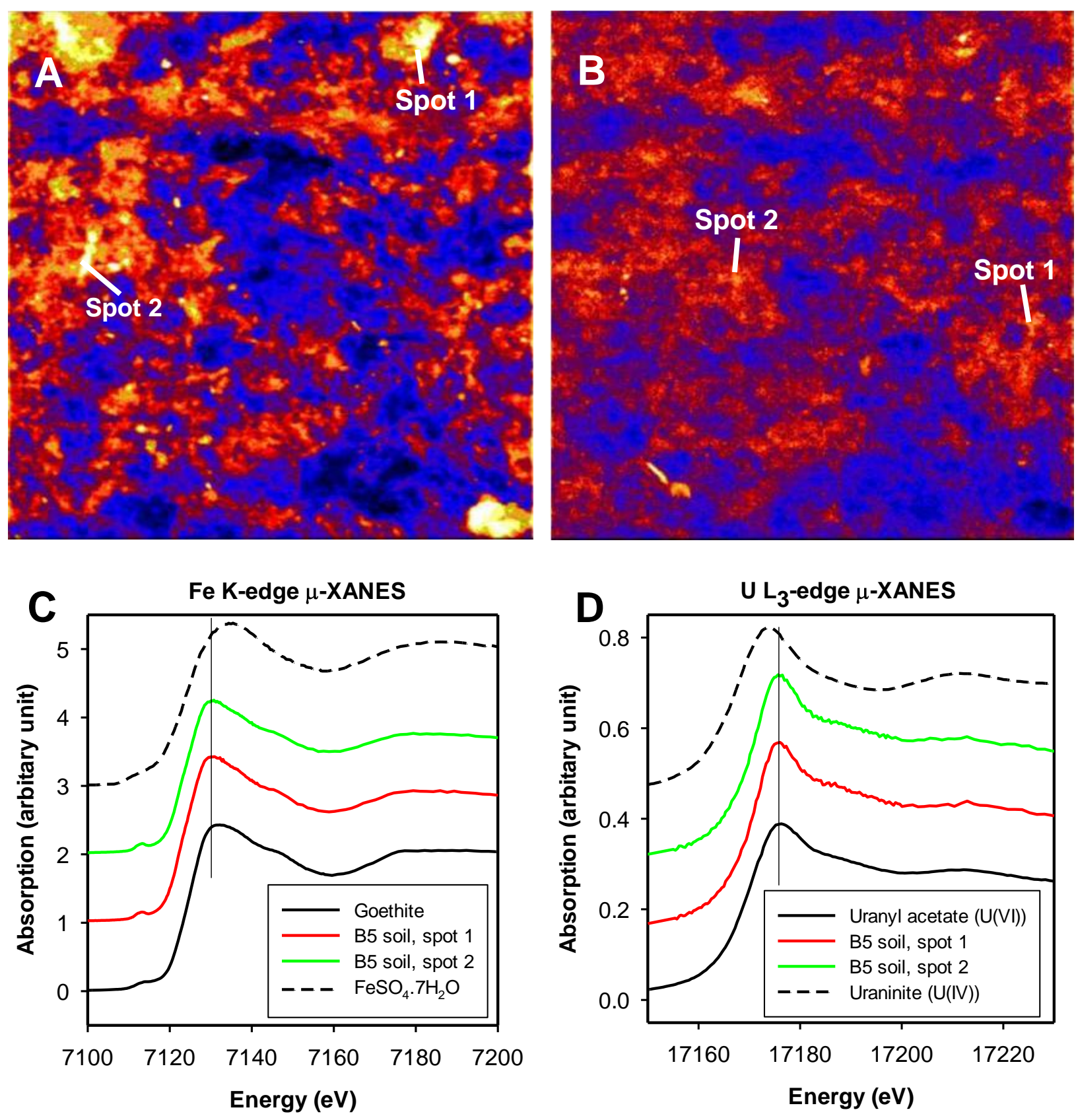

Fig. 7. XAS analyses of uranium-contaminated bulk soil recovered from Tims Branch wetland. $\mu$-XRF maps of (A) iron and (B) uranium. (C) Fe K-edge $\mu$-XANES spectra of two hotspots, and two standards (Fe(III) - goethite and $\mathrm{Fe}(\mathrm{II})-\mathrm{FeSO}_{4} \cdot 7 \mathrm{H}_{2} \mathrm{O}$ ). (D) $\mathrm{U} \mathrm{L}_{3}$ edge $\mu$-XANES of two hotspots and two standards (U(VI) - uranyl acetate and U(IV) uraninite). 

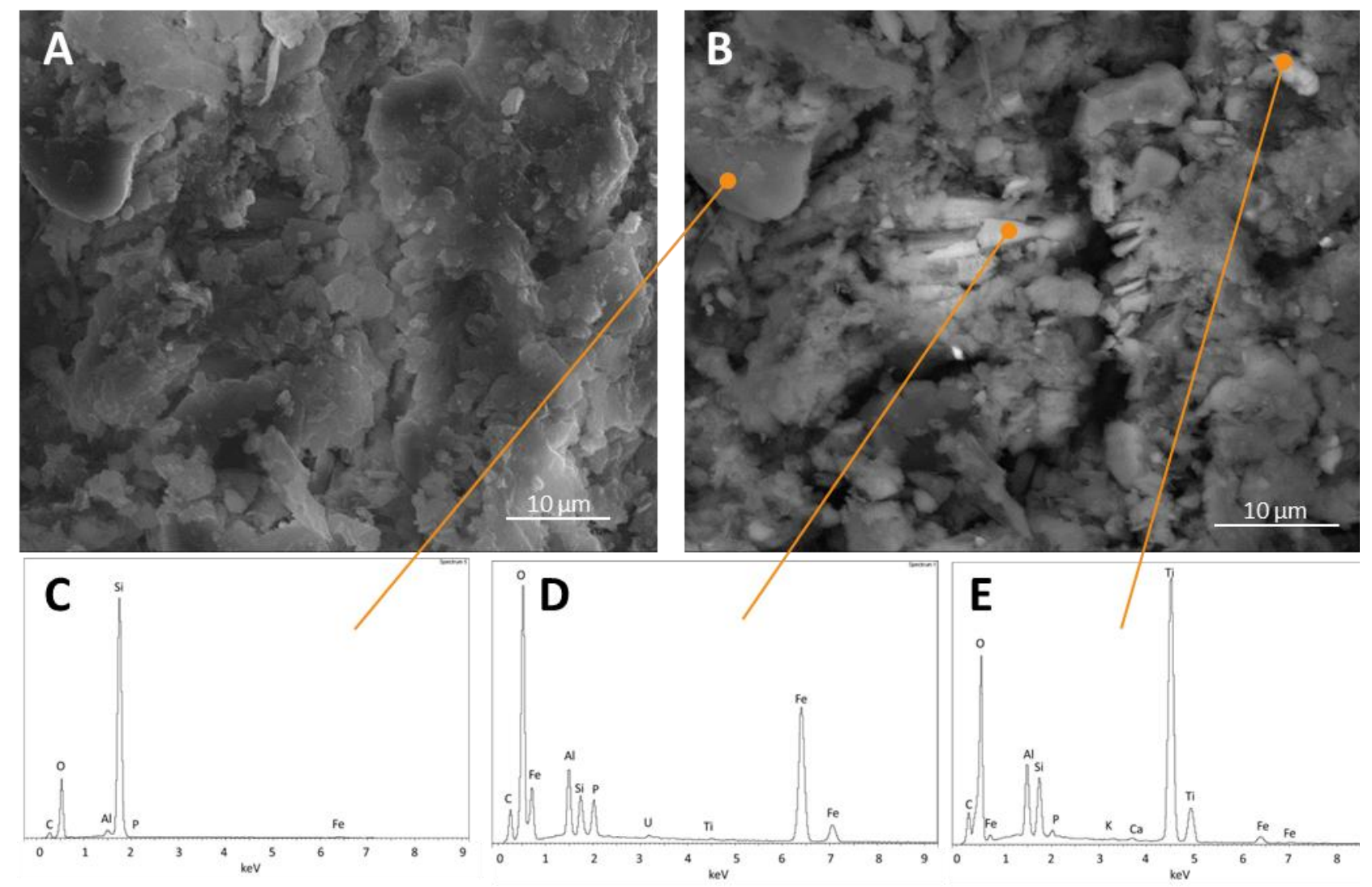

Fig. 8. Examples of SEM images taken at the same location on a root plaque recovered from the \#1-Contaminated site in (A) direct mode and (B) in backscatter mode. Examples of EDS spectra demonstrating that $(C)$ particles with little or no detectable $P$ or dominated by Si did not have detectable $U$; (D) $U$ was always found in association with $P$, and commonly existed on particles with $\mathrm{Si} / \mathrm{Al}$ and large $\mathrm{Fe}$ peaks, and $(\mathrm{E}) \mathrm{U}$ was never found in association with particles that had strong Ti peaks and no associated Fe peaks. 